\title{
Evaluation in Cellulose Nanocrystals Effectiveness on Composite Film based Wound Dressing from Poly(vinyl alcohol) and Gum Tragacanth
}

\section{Luong Ngoc Diem}

Kasetsart University - Bangkhen Campus: Kasetsart University

Indranil Banerjee

Indian Institute of Technology Jodhpur

Kunal Pal

National Institute of Technology Rourkela

Udomlak Sukatta

Kasetsart University - Bangkhen Campus: Kasetsart University

Prapassorn Rugthaworn

Kasetsart University - Bangkhen Campus: Kasetsart University

Prakit Sukyai ( $\sim$ fagipks@ku.ac.th )

Kasetsart University Faculty of Agro Industry https://orcid.org/0000-0003-3602-7208

\section{Research Article}

Keywords: Cellulose nanocrystals, Gum tragacanth, Poly(vinyl alcohol), Wound dressing

Posted Date: December 15th, 2021

DOI: https://doi.org/10.21203/rs.3.rs-1094285/v1

License: (1) This work is licensed under a Creative Commons Attribution 4.0 International License.

Read Full License 


\section{Abstract}

Biomaterial-based wound dressings were fabricated using cellulose nanocrystals (CNCs) as nano-filler in a polymeric mixture of poly(vinyl alcohol) (PVA) and gum tragacanth (GT) via solution casting. Physical and chemical characteristics of neat PVA, PVA/GT and PVA/GT/CNC films with varying concentrations (2 to $10 \%$ ) of CNCs were observed. Initial analysis of CNCs showed nanosized particles of $104 \mathrm{~nm}$ length and $7 \mathrm{~nm}$ width. Scanning electron microscopy (SEM) illustrated cluster formations of CNCs in the polymer matrix. Fourier transform infrared (FTIR) spectrometry was used to confirm the chemical functional groups in the material. The presence of GT and CNCs in the polymer matrix improved water uptake and prolonged stability for 7 days. The CNCs enhanced tensile strength from $54.63 \mathrm{MPa}$ to 80.39MPa. Biological properties of PVA/GT/CNC films were analyzed. Results showed that the dressing material was nontoxic to mouse fibroblast cells L929, while film loaded with betel leaf extract exhibited excellent antibacterial activities against Staphylococcus aureus DMST 8840 and Pseudomonas aeruginosa TISTR 781, indicating that composite film was suitable for application in wound dressing.

\section{Introduction}

Wound dressing involves complex biochemical and cellular processes as well as associated pathological conditions (Dhivya et al., 2015; Gupta et al., 2019). Different treatment strategies and wound dressings with special properties are required to regenerate damaged tissues. Wound dressing material should fully cover the affected area, contribute a moist environment to prevent contamination and have the ability to absorb exudates on the wound surface. Medicated dressings can degrade rapidly and they must be changed frequently and easily without causing pain or trauma at the wound bed; they must also be nontoxic, and cost effective (Ilenghoven et al., 2017; Jun et al., 2019). Film dressings are commonly applied for superficial injuries to protect skin prone to abrasion or external contamination (Jun et al., 2019). Film transparency allows daily observation without dressing removal and prevents damage to the wound bed (llenghoven et al., 2017). Recent advances in polymer science have led to novel designs of composite materials with unique properties for numerous biomedical applications such as wound dressings.

Natural and synthetic polymers and blended composite materials have been previously investigated. Poly(vinyl alcohol) (PVA) is a linear synthetic polymer with nontoxic, biocompatible, thermostable, water soluble and film forming properties (Xu et al., 2020). PVA has been used as the main matrix with outstanding physical and chemical properties in biomedical applications (Aslam et al., 2018; Teodorescu et al., 2019). However, the scope of PVA application is limited by its instability, insufficient elasticity and lack of cell-specific bioactivities (Teodorescu et al., 2019; Yadav et al., 2017). Several attempts have been made to improve PVA properties by incorporating substances such as chitosan (Lin et al., 2019; Zhang et al., 2015), dextran (Zheng et al., 2019), poly(ion liquid) (Fang et al., 2019) and nanocellulose (Choo et al., 2016; Wahid et al., 2019). PVA-based wound dressings were also reported including PVA composite films containing bacterial cellulose and epsilon poly-lysine (Wahid et al., 2019), PVA and dextran aldehyde hydrogel (Zheng et al., 2019) and silk fibroin-PVA composite film coated with chitosan-ZnO nanoparticles (Patil et al., 2019). These dressings demonstrated good absorb ability, tissue regeneration with low 
cytotoxicity and inhibited bacterial infections with enhanced mechanical properties but the dressing materials lacked essential features such as good swelling properties and mediated angiogenesis.

Gum tragacanth (GT) is one of the most abundant and renewable natural raw materials. GT is readily accessible, relatively affordable, non-toxic, biocompatible, environmentally friendly and widely used in biomedical science (Taghavizadeh Yazdi et al., 2021) as a natural polysaccharide gum applied in various biotechnological industries (Ahmad et al., 2019). GT comprises a complex mixture of highly branched heterogeneous hydrophilic polysaccharides as mainly D-galacturonic acid and other sugar units with numerous functional groups that provide a suitable medium for cell growth and mediated angiogenesis (Ahmad et al., 2019; Nazarzadeh Zare et al., 2019; Ranjbar-Mohammadi et al., 2016). GT has been incorporated into PVA in applications such as drug delivery (Abdoli et al., 2020), scaffold (Ranjbar Mohammadi et al., 2020; Zarekhalili et al., 2017) and wound dressing (Ranjbar-Mohammadi et al., 2013; B. Singh et al., 2016).

Cellulose nanocrystals (CNCs) show potential as reinforced fillers with needle-like shapes ranging 100$250 \mathrm{~nm}$ in length and 5-70 $\mathrm{nm}$ in width, with high aspect ratio and high crystallinity (Khoo et al., 2018). Dispersion of CNCs in polymers will provides good mechanical properties due to their unique crystalline regions with inherent stability that contributes stiffness and elasticity to the material (Du et al., 2019). CNCs have zero or low toxicity and can stimulate long-term cell proliferation (Seabra et al., 2018). Hence, CNCs have been applied in various aspects of medical applications. Antimicrobial activity is also an important factor for wound dressing materials, and prevents contamination or bacterial infection while improving the healing process. Plant-based bioactive compounds are widely used an antibacterial agent

in wound dressings (Avila-Salas et al., 2019; Gaspar-Pintiliescu et al., 2019). Betel leaf (Piper bet/e L.) is a traditional herbal medicine commonly found in Southeast Asia and East African countries (M. Madhumita et al., 2020; Umar et al., 2018) that contains phenolics, ethanolics, flavonoids, alcohols, alkaloids, terpenes, fatty acids and organic acids. These compounds exhibit several biological antibacterial, antifungal, anti-inflammatory and antioxidant activities (Datta et al., 2011; Dwivedi and Tripathi, 2014; M. Madhumita et al., 2020; Taukoorah et al., 2016).

Here, PVA, GT and CNCs were utilized to produce biomaterial-based wound dressings. Biological properties of PVA/GT/CNC were examined for the film's ability to promote cell growth and prevent bacterial infection by loading crude betel leaf extract as an antimicrobial agent. Physicochemical characteristics of PVA/GT/CNC films were evaluated by scanning electron microscopy, transmission electron microscopy, mechanical tests and swelling capacity.

\section{Experimental}

\section{Nanocellulose extraction from sugarcane bagasse (SCB)}

SCB was dried at $55^{\circ} \mathrm{C}$ for $24 \mathrm{~h}$ and then treated by steam explosion (Nitto Koatsu, Japan) at $190{ }^{\circ} \mathrm{C}$ with a pressure of $13 \mathrm{MPa}$ for $15 \mathrm{~min}$ (Rocha et al., 2012). The exploded sample without sugar-rich liquid 
fraction was continuously treated with $1.4 \% \mathrm{w} / \mathrm{w} \mathrm{NaClO}$ in diluted $\mathrm{CH}_{3} \mathrm{COOH}$ at $70{ }^{\circ} \mathrm{C}$. Bleaching chemicals were added every hour until the sample turned white. The bleached sample was then filtered and washed several times until the pH was neutral (N. T. Lam, W. Saewong, et al., 2017; Sukyai et al., 2018). Dried bleached cellulose fibers were dispersed in $64 \% \mathrm{~W} / \mathrm{v} \mathrm{H}_{2} \mathrm{SO}_{4}$ at $1: 20$ solid-liquid ratio with constant stirring $500 \mathrm{rpm}$ for $75 \mathrm{~min}$ at $45^{\circ} \mathrm{C}$. The hydrolysis reaction was stopped using cold deionized (DI) water and repeated centrifugation at $15,000 \mathrm{rpm}$ for $15 \mathrm{~min}$ at $4{ }^{\circ} \mathrm{C}$. The supernatant was removed and replaced by clean DI water, followed by dialysis. Afterward, the CNCs were sonicated (Bransonic Model 2201R-MT, USA) and kept at $4{ }^{\circ} \mathrm{C}$ until required for further use.

\section{Preparation of composite films}

An aqueous solution of PVA ( $10 \% \mathrm{w} / \mathrm{v})$ was prepared under continuous stirring at $80{ }^{\circ} \mathrm{C}$, and $10 \% \mathrm{w} / \mathrm{w}$ of GT based on a specific amount of PVA was added to create PVA/GT solution (Yadav et al., 2017). CNC composite films were fabricated by adding CNC suspension varying from $2-10 \%$ to PVA/GT solution, denoted as PVA/GT/CNC2 to PVA/GT/CNC10. The mixtures were stirred for 30 min to obtain a homogenous state before pouring into Petri dishes and drying at $37{ }^{\circ} \mathrm{C}$ for $48 \mathrm{~h}$. The dried films were soaked in crude betel leaf extract prepared in propylene glycol (PG) at different concentrations $(2 \%, 3 \%$ and $4 \%$ ) for $24 \mathrm{~h}$ and dried at $37^{\circ} \mathrm{C}$ as the antimicrobial agent.

\section{Transmission electron microscopy (TEM)}

CNC particle dimensions were examined by TEM. Briefly, $0.01 \% \mathrm{w} / \mathrm{v}$ CNC suspension was deposited on a carbon-coated copper grid, post-stained with $2 \% \mathrm{w} / \mathrm{v}$ uranyl acetate solution and dried for $8 \mathrm{~min}$. The sample was analyzed under TEM (Hitachi Model HT7700, Japan) with an accelerating voltage of $100 \mathrm{kV}$. CNC dimensions were determined using the ImageJ program.

\section{Optical and transparency measurement}

Film transparency was determined using a Genesys $10 \mathrm{~S}$ UV-Vis spectrophotometer (Thermo Fisher Scientific, USA) at a wavelength of $560 \mathrm{~nm}$ (Vanitjinda et al., 2019). Film specimens were cut into rectangular shapes $(2 \times 40 \mathrm{~mm})$ and placed inside the spectrophotometer cells. An empty spectrophotometer cell was set as a blank. All measurements were conducted in triplicate. The percentage of film transparency was calculated using the formula (1) (Mostafavi et al., 2016):

$\% T=\left(T_{f} / T_{b}\right) \times 100(1)$

where $T_{f}$ and $T_{b}$ are the transmittance values of the film sample and blank cell, respectively.

\section{Scanning electron microscopy (SEM)}

Surface and cross section of the composite films were investigated by SEM (Hitachi Model, Joel JSM5600LV, Japan) with an accelerating voltage of 15-20 kV. To observe the cross section, film specimens were freeze-cracked following immersion in liquid nitrogen. Each piece was deposited on a cylindrical holder and coated with a thin gold layer before observation. 


\section{Fourier transform infrared (FTIR) spectrometry analysis}

PVA, PVA/GT and PVA/GT/CNC composite films were cut into $10 \times 10 \mathrm{~mm}$ squares at random locations. Infrared spectra of each sample were recorded using an FTIR (Bruker Tensor 27 Spectrometer, USA) in the range of 4000-500 $\mathrm{cm}^{-1}$ with a resolution of $4 \mathrm{~cm}^{-1}$.

\section{Swelling ratio and stability}

Swelling ratio and stability of the composite films were evaluated based on the amount of water absorbed and percentage of weight loss after 7 days, respectively. Briefly, dried film specimens $(15 \times 15$ $\mathrm{mm}$ ) were immersed in DI water at ambient temperature. For each turn of measurement (Popescu et al., 2017), swelling ratio was assessed by the weight of swollen samples. To examine the stability of composite films, swollen samples were taken and dried again to measure the difference in dried weight before and after immersion. All samples were weighed by an analytical balance with three replications and results were calculated using the formulae (2) and (3) (Zheng et al., 2019):

Swelling ratio $=\left(M_{1}-M_{0}\right) / M_{0} \times 100(2)$

Weight loss $=\left(M_{0}-M_{1}\right) / M_{0} \times 100(3)$

where $M_{0}$ and $M_{1}$ represent sample weight before and after immersion, respectively.

\section{Mechanical properties}

Tensile strength and elongation at break of the composite films were evaluated using a universal testing machine (AGS-J 1kN, Japan) according to ASTM D882-02 Standard Method. Briefly, films were cut into rectangular shapes $(10 \times 50 \mathrm{~mm})$ and kept at $25^{\circ} \mathrm{C}$ with relative humidity of $50 \% \pm 2 \%$ until reaching constant weight. The films were tightly fixed in the grips with $30 \mathrm{~mm}$ initial space and pulled apart by a 1 $\mathrm{kN}$ load cell. The experiment was repeated as three replications, and tensile strength and elongation at break were calculated from the formulae (4) and (5), respectively (Mostafavi et al., 2016):

Tensile strength $=F /(T \times W)(4)$

where $F, T$ and $X$ are the maximum force, film thickness and width of film, respectively.

Elongation at break $=\left(D_{1}-D_{0}\right) \times 100(5)$

where $D_{1}$ is the distance of rupture and $D_{0}$ is the initial distance between grips.

\section{Cytotoxicity}

Cytotoxicity testing was conducted using the colorimetric MTT assay of tetrazolium dye that evaluated 3(4,5-dimethylthiazol-2-yl)-2,5-diphenyltetrazolium bromide following the on ISO 10993-5 standard (Simon, 2004). Mouse fibroblast cells L929 (NCTC clone 929:CCL1 from the American Type Culture Collection (ATCC), strain L) were cultured in Minimum Essential Medium (MEM) with an appropriate cell density of 
$10^{5} \mathrm{cells} / \mathrm{ml}$ and incubated for $24 \pm 2 \mathrm{~h}$. The films were sterilized by UV irritation for $15 \mathrm{~min}$, prepared at 3 $\mathrm{cm}^{2} / \mathrm{ml}$ and extracted for $24 \pm 2 \mathrm{~h}$ at $37 \pm 1{ }^{\circ} \mathrm{C}$. The extracts were further incubated for $24 \pm 2 \mathrm{~h}$ before being stained with MTT assay for $2 \mathrm{~h}$. A Thermanox (Nunc) coverslip was used as the negative control, while polyurethane film containing $0.1 \%$ zinc diethyldithiocarbamate served as the positive control. A culturing with fibroblast cells for $24 \mathrm{~h}$, tested samples were compared to the negative and positive controls. A microplate reader was used to determine cell viability at absorbance of $570 \mathrm{~nm}$ using equation (6) (Ranjbar-Mohammadi et al., 2013). Cell viability above $70 \%$ was considered non-cytotoxic.

Cell viability $=O D_{\text {sample }} / O D_{\text {blank }} \times 100 \%(6)$

where $\mathrm{OD}_{\text {sample }}$ and $\mathrm{OD}_{\text {blank }}$ are measurements of optical density of the test sample and blank sample, respectively.

\section{Antimicrobial ability}

Antimicrobial properties of films loaded with crude betel leaf extract were studied against Staphylococcus aureus DMST 8840 and Pseudomonas aeruginosa TISTR 781 using the agar diffusion method. Before the experiment, $S$. aureus and $P$. aeruginosa suspensions of $10^{6} \mathrm{CFU} / \mathrm{ml}$ were evenly spread over nutrient agar plates. Films loaded with betel leaf extract were placed on an inoculated agar surface, with paper discs loaded with erythromycin used as the positive control and PG as the negative control. The culture plates were incubated at $37^{\circ} \mathrm{C}$ for $18 \mathrm{~h}$, and the inhibition zone was measured at the end of the incubation time.

\section{Statistical analysis}

Statistical analysis of the experimental data was performed by one-way analysis of variance (ANOVA) at a confidence level of 0.05 using the Minitab program. All data were expressed as mean \pm standard deviation. A p-value $<0.05$ was considered statistically significant.

\section{Results And Discussion}

SCB (Fig. 1a) consists of cellulosic and non-cellulosic components. A series of treatment steps were conducted to remove the non-cellulosic components (hemicellulose and lignin) to promote defibrillation. Removal of major non-cellulosic components increased the cellulose content. The bleached fiber (Fig. 1b) was subsequently applied in acid hydrolysis that caused disordering in the glycosidic linkages and breakdown of the fibrous structure, resulted in reduction of fiber size of CNCs (Tong et al., 2017). The crystalline CNCs were presented as a stable colloidal suspension (Fig. 1c). The surface of CNCs was linked to negatively charged particles of sulfate half ester groups derived from the acid hydrolysis process (Du et al., 2019). TEM analysis was carried out to determine particle size and distribution of CNCs. Results showed needle-like shapes of individual and aggregated particles (Fig. 1d). Dimensions of the CNCs were approximately $104 \mathrm{~nm}$ in length and $7 \mathrm{~nm}$ in width, similar to sizes reported earlier (N. Lam et al., 2017; Meesupthong et al., 2020). 
Results in Table 1 show the percentage transparency of the composite films. Neat PVA recorded the highest transmittance of $91.27 \pm 0.43 \%$ followed by PVA/GT at $74.59 \pm 0.43 \%$. The PVA/GT/CNC10 film recorded the lowest transmittance of $46.28 \pm 0.54 \%$. High significant difference $(p<0.05)$ was recorded between PVA, PVA/GT and PVA/GT/CNC composite films due to differences in light dispersion caused by the disparate viscosities of GT and PVA (Silva et al., 2016) and aggregation of CNCs as the concentration increased (Chen et al., 2020). Optical properties also related the re-arrangements in the internal structure of PVA molecules during the drying process (Silva et al., 2016; Tonyali et al., 2018). Opaqueness of the films increased at higher CNC concentration (Table 1) although visual observations of composite films were recorded as colorless and transparent (Fig. 2). Films with the lowest and highest concentration of CNCs were selected for SEM analysis.

Table 1

Transparency of composite film.

\begin{tabular}{|ll|}
\hline Samples & Transmittance \\
PVA & $91.27 \pm 0.43^{\mathrm{b}}$ \\
PVA/GT & $74.59 \pm 0.43^{\mathrm{c}}$ \\
PVA/GT/CNC4 & $74.30 \pm 0.17^{\mathrm{c}}$ \\
PVA/GT/CNC6 & $68.94 \pm 0.11^{\mathrm{d}}$ \\
PVA/GT/CNC8 & $68.79 \pm 0.11^{\mathrm{d}}$ \\
PVA/GT/CNC10 & $59.70 \pm 0.39^{\mathrm{e}}$ \\
Control (Blank) & $46.28 \pm 0.54^{\mathrm{f}}$ \\
& $100 \pm 0.00^{\mathrm{a}}$ \\
\hline & \\
\hline
\end{tabular}

SEM micrographs showed the surface and cross section of PVA, PVA/GT and PVA/GT/CNC films (Fig. 3). Neat PVA film had a uniform texture with a smooth planer surface and cross section (Fig. 3a and e). However, when GT was added, the film surface became slightly rougher, characterized by the presence of white dots on the surface and cracks in the cross section (Fig. 3b and f). Mostafavi et al. (2016) reported that the chemical structure of GT could organize into a more open and porous network. Similarly, blended film containing GT showed reduced homogeneous quality (Khodaei et al., 2019; Tonyali et al., 2018) support swelling capacity. Dispersion of nanocellulose in the PVA/GT films (Fig. 3c) resulted in the disappearance of some white dots on the surface structure, suggesting that CNC particles filled in the polymeric matrix. Increasing the CNCs content led to assemblage and cluster formation of CNCs in the film (Fig. 3d). This result concurred with Jahan et al. (2018). In addition, CNC distribution was observed 
on the fractured shapes in the cross section (Fig. $3 g$ and $h$ ). The nanocellulose reinforced polymer network formed aggregates with a wide range of sizes and shapes in random directions (Mandal and Chakrabarty, 2015). Higher concentrations of nanocellulose induced brittle fracture because the aggregates were able to concentrate force at localized points, thus impacting mechanical properties.

Figure 4 shows the FTIR analysis of chemical functional groups of GT powder, PVA, PVA/GT and PVA/GT/CNC films. The FTIR spectra for GT powder with an absorption band at $2149 \mathrm{~cm}^{-1}$ corresponded to various carbonyl groups in the gum while peaks of carbonyl stretching in aldehydes, ketones and carboxylic acids were presented at $1750 \mathrm{~cm}^{-1}$ (Kurt, 2018). The bands at $1635 \mathrm{~cm}^{-1}$ and $1442 \mathrm{~cm}^{-1}$ were attributed to asymmetrical and symmetrical stretching of carboxylate groups, respectively, while peaks at $1242 \mathrm{~cm}^{-1}$ and $1020 \mathrm{~cm}^{-1}$ displayed C-O stretching vibration in polyols and alcoholic groups, respectively (Abdoli et al., 2020; Ranjbar-Mohammadi et al., 2013; Zarekhalili et al., 2017). The band observed in all samples at $3285 \mathrm{~cm}^{-1}$ was characteristic of $\mathrm{O}-\mathrm{H}$ stretching groups from intra- and intermolecular hydrogen bonds (Choo et al., 2016; Jahan et al., 2018) while a wider band of O-H stretching in the GT structure observed at $3420 \mathrm{~cm}^{-1}$ was caused by $\mathrm{OH}$ and $\mathrm{COOH}$ groups (Mostafavi et al., 2016; RanjbarMohammadi et al., 2013). Asymmetrical and symmetrical stretching vibrations of methylene groups were presented at $2939 \mathrm{~cm}^{-1}$ and $2908 \mathrm{~cm}^{-1}$, respectively (Zarekhalili et al., 2017) while the peak at $1086 \mathrm{~cm}^{-1}$ was assigned to C-O stretching (Jahan et al., 2018; Mostafavi et al., 2016). Vinyl C-H in plane bending of PVA was confirmed at $1419 \mathrm{~cm}^{-1}$. Furthermore, the absorption band centered at $842 \mathrm{~cm}^{-1}$ represented $C=C$ bending (Abureesh et al., 2016; Mandal and Chakrabarty, 2015). No significant change in PVA matrix was recorded after the incorporation of GT and CNCs, with no effect on PVA molecule structure and so its chemical structures were maintained (S. Singh et al., 2018). Notably, addition of CNCs at high concentration contributed C『C stretching at $1655 \mathrm{~cm}^{-1}$ (Nandiyanto et al., 2019).

Swelling of wound dressing is an important factor that relates to wound exudates absorption and prevention of infection and can be explained by physical and chemical changes in material structure that help water molecules to diffuse internally, leading to an increase in free volume (Jahan et al., 2018; Kumar et al., 2014; Sadat Hosseini et al., 2016). Results in Fig. 5 showed the swelling ability of the various films. Initially, the large numbers of free hydroxyl groups in PVA film absorbed water molecules and reached the maximum state of approximately $260 \%$ before reducing at $1.5 \mathrm{~h}$. PVA/GT films increased gradually and then remained at a steady rate of $250 \%$ due to the presence of hydrogen bonds in hydroxyl and carboxyl functional groups (Kurt, 2018). The porous structure of GT trapped water molecules (Khodaei et al., 2019; Nazarzadeh Zare et al., 2019; Rao et al., 2017). After 6 h, water content slightly decreased to $230 \%$ up to 7 days due to degradation in some linking points in the polymer matrix (Tavakol et al., 2014). There were no obvious differences in PVA/GT/CNC2 and PVA/GT films. Addition of small amounts of CNCs increased water absorption in the polymer matrix. However, as CNC concentration increased, extra swelling capacity was restrained (Jahan et al., 2018; Popescu et al., 2017; Sutka et al., 2015) due to the reinforcing effects of CNCs. This reduction illustrated that hydrogen bonding between CNC groups. Thus, water molecules could not freely pass through the polymer (Slavutsky and Bertuzzi, 2014; Sutka et al., 2015). The PVA/GT/CNC2 film provided swelling behavior that could create an 
environment suitable for wound healing (Fang et al., 2019; Patil et al., 2019; Sadat Hosseini et al., 2016; Zhao et al., 2017).

Stability of the wound dressing was assessed as the percentage weight loss of composite film to indicate prolonged use (Zheng et al., 2019). Results in Fig. 6 showed the PVA films exhibited the highest rate of weight loss of $9.8 \%$ on the first day, and this increased to $17.2 \%$ on the 7 th day due to solvation and fragmentation of the film (Kumar et al., 2014). However, addition of GT improved film stability by maintaining weight loss below $12 \%$ after 7 days. Bassorin fragments in GT are insoluble in water, thus reducing the film solubility (Pirsa et al., 2020). Solubility was further reduced after 7 days when CNCs were added due to the formation of a strong matrix of hydrogen bonds through the three-dimensional structure of CNCs and the polymeric matrix that reduced free hydroxyl groups and restricted water penetration (Popescu et al., 2017; Slavutsky and Bertuzzi, 2014).

Mechanical properties of the films are summarized in Table 2. Wound dressing should be strong, flexible and elastic for efficient treatment; thus, the film was evaluated in terms of tensile strength, elongation at break and elastic modulus (Tong et al., 2017). Neat PVA film exhibited tensile strength of $54.63 \mathrm{MPa}$, which reduced slightly to $49.26 \mathrm{MPa}$ when GT was added. There was no significant difference $(p<0.05)$ between neat PVA and PVA/GT. This result concurred with by Ojagh et al. (2017) who found that addition of GT had no significant effect on mechanical properties. Highest tensile strength was recorded by PVA/GT/CNC2 (80.39MPa), while PVA/GT/CNC6 gave the lowest strength of $45.05 \pm 3.39 \mathrm{MPa}$. Small amounts of nanocellulose increased the strength of the material by entrapping nano-filler inside the matrix. This allowed strong hydrogen bond formation between nanocellulose and matrix, thus imparting mechanical integrity (N. Lam et al., 2017; Sun et al., 2017). However, high concentration of CNCs led to agglomeration of particles, increased rigidity and poor distribution in polymer matrices, thus impacting the formation of hydrogen bonds among polymer chains and inhibiting reinforcing properties (Choo et al., 2016; Mandal and Chakrabarty, 2015). Elastic modulus values of PVA and PVA/GT were $1223.08 \pm$ 182.08 MPa and $1062.51 \pm 101.65 \mathrm{MPa}$, respectively. Highest elastic modulus of $1526.11 \pm 31.86 \mathrm{MPa}$ was recorded by PVA/GT/CNC2 film, which decreased to $1260.45 \pm 76.94 \mathrm{MPa}$ in PVA/GT/CNC10 film. The high value was attributed to the crystalline nature of CNCs that resulted in better alignment and enhanced elastic modulus (Jahan et al., 2018; Sun et al., 2017). Although there was no significant difference in elastic modulus, composite materials loaded with CNCs showed higher values than neat PVA and PVA/GT samples. Mechanical properties of wound dressing were recommended to cover the mechanical properties of human skin (5-30 MPa) depending on body region (Bombaldi de Souza et al., 2020). Improvement in tensile strength should be adequate for application and storage, to ensure that the dressing is not be damaged by handling (Elsner et al., 2012; Pires and Moraes, 2014). Therefore, PVA/GT/CNC composite materials in the range of 45-80 MPa showed good mechanical properties compared to previous studies (Pires and Moraes, 2014; Schoeler et al., 2020; Tong et al., 2017). Neat PVA had elongation at break of $48.52 \%$ and this slightly decreased to $44.48 \%$ in PVA/GT, while elongation at break of PVA/GT/CNC films decreased with increasing concentration of CNCs. The elongation at break significantly decreased to $8.11 \%$ in PVA/GT/CNC2 and continuously dropped to $3.92 \%$ in PVA/GT/CNC10 film due to the rigid nature of CNCs. The rough structure with cracks inside the polymer matrix (Fig. $3 \mathrm{~h}$ ) 
led to the material being easily broken easily under pressure (Mandal and Chakrabarty, 2015). Since CNCs are not deformable, strong interaction between CNCs and the matrix did not allow elongation in the composite materials (Ching et al., 2015).

Table 2

Mechanical properties of composite films.

\begin{tabular}{|llll|}
\hline Sample & $\begin{array}{l}\text { Tensile strength } \\
(\mathrm{MPa})\end{array}$ & $\begin{array}{l}\text { Elongation at break } \\
(\%)\end{array}$ & $\begin{array}{l}\text { Elastic modulus } \\
(\mathrm{MPa})\end{array}$ \\
\hline PVA & $54.63 \pm 0.69^{\mathrm{bc}}$ & $48.52 \pm 1.57^{\mathrm{a}}$ & $1223.08 \pm 182.08^{\mathrm{a}}$ \\
$\mathrm{PVA} / \mathrm{GT}$ & $49.26 \pm 5.00^{\mathrm{bc}}$ & $44.38 \pm 5.03^{\mathrm{a}}$ & $1062.51 \pm 101.65^{\mathrm{a}}$ \\
$\mathrm{PVA} / \mathrm{GT} / \mathrm{CNC2}$ & $80.39 \pm 1.41^{\mathrm{a}}$ & $8.11 \pm 0.30^{\mathrm{b}}$ & $1526.11 \pm 31.86^{\mathrm{a}}$ \\
$\mathrm{PVA} / \mathrm{GT} / \mathrm{CNC4}$ & $59.09 \pm 4.26^{\mathrm{b}}$ & $7.36 \pm 0.82^{\mathrm{b}}$ & $1450.74 \pm 76.94^{\mathrm{a}}$ \\
$\mathrm{PVA} / \mathrm{GT} / \mathrm{CNC6}$ & $45.05 \pm 3.39^{\mathrm{c}}$ & $8.81 \pm 1.56^{\mathrm{b}}$ & $1299.13 \pm 120.37^{\mathrm{a}}$ \\
$\mathrm{PVA} / \mathrm{GT} / \mathrm{CNC8}$ & $47.63 \pm 3.54^{\mathrm{bc}}$ & $6.88 \pm 0.06^{\mathrm{b}}$ & $1353.38 \pm 177.19^{\mathrm{a}}$ \\
PVA/GT/CNC10 & $47.68 \pm 9.26^{\mathrm{bc}}$ & $3.92 \pm 0.92^{\mathrm{b}}$ & $1260.45 \pm 76.94^{\mathrm{a}}$ \\
\hline
\end{tabular}

The cytotoxicities of PVA, PVA/GT, and PVA/GT/CNC10 films were evaluated using the MTT assay. The sample with the highest CNC concentration (PVA/GT/CNC10) was tested to confirm non-toxicity and safety of the film for cell growth. Results showed significant differences between test samples and the positive control, while there were no significant differences between the test samples and the negative control (Fig. 8). Cell viabilities of PVA and PVA/GT were $93 \%$ and $84 \%$, respectively. Decrease in cell viability of PVA/GT film may be due to the diversity in chemical composition that slightly influenced the biological properties (Nazarzadeh Zare et al., 2019). The high concentration of CNCs was found to be non-toxic to fibroblast cells with $95 \%$ cell viability. Incorporation of CNCs in the polymeric matrix and reaction between CNCs and PVA/GT improved cell viability in the films. All samples were non-toxic to fibroblast cells and satisfied non-cytotoxic requirement of cell viability above $70 \%$, in agreement with results reported by previous studies (N. T. Lam, R. Chollakup, et al., 2017; Zarekhalili et al., 2017).

Disc diffusion results revealed that films loaded with betel leaf extract at different concentrations of $2 \%$, $3 \%$ and $4 \%$, exhibited excellent antibacterial activity against both gram-negative (P. aeruginosa) and gram-positive (S. aureus) microorganisms. According to Othman et al. (2018), antibacterial activity of betel leaf extract started to be observed at $100 \mathrm{mg} / \mathrm{ml}$. Results in Fig. 9 show clear zones around discs, in agreement with previous studies (Akter et al., 2014; Mitali Madhumita et al., 2019; Taukoorah et al., 2016). The inhibition zone increased with increasing concentration of betel leaf extract. The susceptibility of $P$. aeruginosa was less than $S$. aureus (Table 3 ) due to differences in their morphology. The essential oil 
contained in betel leaf extract inhibited bacterial cell growth due to hydroxyl groups in the phenolic compounds and the hydrophobicity of fatty acids and hydroxyl fatty acid ester components. These groups caused destabilization on the cytoplasmic membrane disrupted proton and electron flow and discharge ATP/decreased ATP synthesis leading to cell death (Nouri and Mohammadi Nafchi, 2014; Umar et al., 2018). The zone of inhibition of $P$. aeruginosa was less than $S$. aureus due to the outer layer of phospholipidic membrane that contributed an impermeable strong cell wall (Arias et al., 2004; Umar et al., 2018). The films showed higher inhibition zones than the positive control, while the negative control did not show any inhibition in both strains, proving that betel leaf extract activity was not affected by PG.

Table 3

Antimicrobial activity of PVA/GT/CNC2 film loaded betel extract on agar diffusion test.

\begin{tabular}{|lll|}
\hline Sample & \multicolumn{2}{l|}{ Diameter of inhibition zone $(\mathrm{mm})$} \\
\cline { 2 - 3 } & P. aeruginosa & S. aureus \\
\hline Betel 2\% & $16.60 \pm 3.21^{\mathrm{b}}$ & $18.00 \pm 1.87^{\mathrm{c}}$ \\
Betel 3\% & $19.00 \pm 1.41^{\mathrm{b}}$ & $22.00 \pm 3.83^{\mathrm{b}}$ \\
Betel 4\% & $23.60 \pm 0.55^{\mathrm{a}}$ & $28.20 \pm 0.84^{\mathrm{a}}$ \\
Positive control & $12.30 \pm 0.57^{\mathrm{c}}$ & $14.40 \pm 1.14^{\mathrm{c}}$ \\
Negative control & - & - \\
\hline
\end{tabular}

\section{Conclusions}

PVA/GT/CNC composite film was successfully prepared as wound dressing material. The PVA/GT/CNC2 film exhibited higher swelling ratio and mechanical properties with good transparency. These properties could help to absorb exudates with easy daily observation, and minimize trauma to the wound bed. Apart from the physicochemical enhancements, cytocompatibility was also verified by mouse fibroblast cells that showed the film to be non-toxic. The film also exhibited excellent antibacterial activity by loading betel leaf extract against both gram-negative ( $P$. aeruginosa) and gram-positive ( $S$. aureus) bacteria. Composite films showed promise as candidates for healing protection in cutaneous wound dressing application.

\section{Declarations}

\section{Funding}

This study was funded by the Thailand-India Program of Science and Technology Cooperation. 


\section{Conflict of interest}

The authors declare that they have no conflict of interest

\section{Human/Animal Rights}

This article does not contain any studies with human or animal subject performed by any authors

\section{Ethical approval}

Not applicable

\section{Consent to participate}

Not applicable

\section{Consent for publication}

Not applicable

\section{Code availability}

Not applicable

\section{Acknowledgements}

The authors are grateful to the Department of Biotechnology, Faculty of Agro-Industry and Kasetsart University, Bangkok, Thailand for an "Agro-Industry (AI) Scholarship for International Students 2018". Support from members of the Biotechnology of Biopolymer and Bioactive Compound Research Unit during various stages of the research was greatly appreciated.

\section{References}

1. Abdoli, M., et al. (2020). Polyvinyl alcohol/Gum tragacanth/graphene oxide composite nanofiber for antibiotic delivery. Journal of Drug Delivery Science and Technology, 60. doi:10.1016/j.jddst.2020.102044

2. Abureesh, M. A., et al. (2016). Facile synthesis of glucose-sensitive chitosan-poly(vinyl alcohol) hydrogel: Drug release optimization and swelling properties. Int J Biol Macromol, 90, 75-80. doi:10.1016/j.ijbiomac.2015.10.001

3. Ahmad, S., et al. (2019). A review on latest innovations in natural gums based hydrogels: Preparations \& applications. Int J Biol Macromol. doi:10.1016/j.ijbiomac.2019.06.113

4. Akter, K. N., et al. (2014). Evaluation of antibacterial and anthelmintic activities with total phenolic contents of Piper betel leaves. Avicenna Journal of Phytomedicine, 4(5), 10. 
5. Arias, M. E., et al. (2004). Antibacterial activity of ethanolic and aqueous extracts of Acacia aroma Gill. ex Hook et Arn. Life Sci, 75(2), 191-202. doi:10.1016/j.lfs.2003.12.007

6. Aslam, M., et al. (2018). Polyvinyl alcohol: A review of research status and use of polyvinyl alcohol based nanocomposites. Polymer Engineering \& Science, 58(12), 2119-2132. doi:10.1002/pen.24855

7. Avila-Salas, F., et al. (2019). Film Dressings Based on Hydrogels: Simultaneous and SustainedRelease of Bioactive Compounds with Wound Healing Properties. Pharmaceutics, 11(9). doi:10.3390/pharmaceutics11090447

8. Bombaldi de Souza, R. F., et al. (2020). Biopolymer-based films and membranes as wound dressings. In Biopolymer Membranes and Films (pp. 165-194).

9. Chen, L., et al. (2020). Highly Transparent and Colorless Nanocellulose/Polyimide Substrates with Enhanced Thermal and Mechanical Properties for Flexible OLED Displays. Advanced Materials Interfaces, 7(20). doi:10.1002/admi.202000928

10. Ching, Y. C., et al. (2015). Preparation and Characterization of Polyvinyl Alcohol- Based Composite Reinforced with Nanocellulose and Nanosilica. BioResources, 10(2), 14.

11. Choo, K., et al. (2016). Preparation and Characterization of Polyvinyl Alcohol-Chitosan Composite Films Reinforced with Cellulose Nanofiber. Materials (Basel), 9(8). doi:10.3390/ma9080644

12. Datta, A., et al. (2011). Antimicrobial Property of Piper betel Leaf against Clinical Isolates of Bacteria. International Journal of Pharma Sciences and Research, 2(3), 6.

13. Dhivya, S., et al. (2015). Wound dressings - a review. Biomedicine (Taipei), 5(4), 22. doi:10.7603/s40681-015-0022-9

14. Du, H., et al. (2019). Cellulose nanocrystals and cellulose nanofibrils based hydrogels for biomedical applications. Carbohydr Polym, 209, 130-144. doi:10.1016/j.carbpol.2019.01.020

15. Dwivedi, V.and Tripathi, S. (2014). Review study on potential activity of Piper betle. Journal of Pharmacognosy and Phytochemistry, 3(4), 6.

16. Elsner, J. J., et al. (2012). Highly porous drug-eluting structures: from wound dressings to stents and scaffolds for tissue regeneration. Biomatter, 2(4), 239-270. doi:10.4161/biom.22838

17. Fang, H., et al. (2019). A novel high-strength poly(ionic liquid)/PVA hydrogel dressing for antibacterial applications. Chemical Engineering Journal, 365, 153-164. doi:10.1016/j.cej.2019.02.030

18. Gaspar-Pintiliescu, A., et al. (2019). Natural composite dressings based on collagen, gelatin and plant bioactive compounds for wound healing: A review. International Journal of Biological Macromolecules, 138, 854-865. doi:https://doi.org/10.1016/j.jibiomac.2019.07.155

19. Gupta, A., et al. (2019). The production and application of hydrogels for wound management: A review. European Polymer Journal, 111, 134-151. doi:10.1016/j.eurpolymj.2018.12.019

20. Ilenghoven, D., et al. (2017). A Review of Wound Dressing Practices. Clinical Dermatology Open Access Journal, 2(6). doi:10.23880/cdoaj-16000133

21. Jahan, Z., et al. (2018). Mechanical, thermal and swelling properties of cellulose nanocrystals/PVA nanocomposites membranes. Journal of Industrial and Engineering Chemistry, 57, 113-124. 
doi:10.1016/j.jiec.2017.08.014

22. Jun, L., et al. (2019). The Wound Dressings and Their Applications in Wound Healing and Management. Health Science, 13(4).

23. Khodaei, D., et al. (2019). Preparation and characterization of blended edible films manufactured using gelatin, tragacanth gum and, Persian gum. Lwt. doi:10.1016/j.Iwt.2019.108617

24. Khoo, R. Z., et al. (2018). Sugarcane bagasse fiber and its cellulose nanocrystals for polymer reinforcement and heavy metal adsorbent: a review. Cellulose, 25(8), 4303-4330. doi:10.1007/s10570-018-1879-z

25. Kumar, A., et al. (2014). Microstructural and mechanical properties of porous biocomposite scaffolds based on polyvinyl alcohol, nano-hydroxyapatite and cellulose nanocrystals. Cellulose, 21(5), 34093426. doi:10.1007/s10570-014-0339-7

26. Kurt, A. (2018). Physicochemical, Rheological and Structural Characteristics of Alcohol Precipitated Fraction of Gum Tragacanth. Food and Health, 183-193. doi:10.3153/fh18019

27. Lam, N., et al. (2017). Characterization of Cellulose Nanocrystals Extracted from Sugarcane Bagasse for Potential Biomedical Materials (Vol. 19).

28. Lam, N. T., et al. (2017). Utilizing cellulose from sugarcane bagasse mixed with poly(vinyl alcohol) for tissue engineering scaffold fabrication. Industrial Crops and Products, 100, 183-197. doi:10.1016/j.indcrop.2017.02.031

29. Lam, N. T., et al. (2017). Effect of varying hydrolysis time on extraction of spherical bacterial cellulose nanocrystals as a reinforcing agent for poly(vinyl alcohol) composites. Journal of Polymer Research, 24(5). doi:10.1007/s10965-017-1232-5

30. Lin, S.-P., et al. (2019). Evaluation of PVA/dextran/chitosan hydrogel for wound dressing. Cellular Polymers, 38(1-2), 15-30. doi:10.1177/0262489319839211

31. Madhumita, M., et al. (2019). Extraction of betel leaves (Piper betle L.) essential oil and its bio-actives identification: Process optimization, GC-MS analysis and anti-microbial activity. Industrial Crops and Products, 138. doi:10.1016/j.indcrop.2019.111578

32. Madhumita, M., et al. (2020). Bio-actives of betel leaf (Piper betle L.): A comprehensive review on extraction, isolation, characterization, and biological activity. Phytother Res. doi:10.1002/ptr.6715

33. Mandal, A.and Chakrabarty, D. (2015). Characterization of nanocellulose reinforced semiinterpenetrating polymer network of poly(vinyl alcohol) \& polyacrylamide composite films. Carbohydr Polym, 134, 240-250. doi:10.1016/j.carbpol.2015.07.093

34. Meesupthong, R., et al. (2020). Xylanase pretreatment of energy cane enables facile cellulose nanocrystal isolation. Cellulose. doi:10.1007/s10570-020-03559-y

35. Mostafavi, F. S., et al. (2016). Preparation and characterization of tragacanth-locust bean gum edible blend films. Carbohydr Polym, 139, 20-27. doi:10.1016/j.carbpol.2015.11.069

36. Nandiyanto, A. B. D., et al. (2019). How to Read and Interpret FTIR Spectroscope of Organic Material. Indonesian Journal of Science and Technology, 4(1). doi:10.17509/ijost.v4i1.15806 
37. Nazarzadeh Zare, E., et al. (2019). Recent progress in the industrial and biomedical applications of tragacanth gum: A review. Carbohydr Polym, 212, 450-467. doi:10.1016/j.carbpol.2019.02.076

38. Nouri, L.and Mohammadi Nafchi, A. (2014). Antibacterial, mechanical, and barrier properties of sago starch film incorporated with Betel leaves extract. Int J Biol Macromol, 66, 254-259. doi:10.1016/j.jibiomac.2014.02.044

39. Ojagh, S. M., et al. (2017). Preparation of chitosan/tragacanth composite film and evaluation of its mechanical and physical properties. Innovative Food Technologies, 4(3), 10. doi:10.22104/jift.2017.417

40. Othman, A. B., et al. (2018). In vitro antimicrobial activity of betel, Piper betle leaf extract against Vibrio alginolyticus isolated from Asian sea bass, Lates calcarifer. Journal of Applied Biology \& Biotechnology, 46-48. doi:10.7324/jabb.2018.60409

41. Patil, P. P., et al. (2019). Hybrid chitosan-ZnO nanoparticles coated with a sonochemical technique on silk fibroin-PVA composite film: A synergistic antibacterial activity. Int J Biol Macromol, 122, 13051312. doi:10.1016/j.jijbiomac.2018.09.090

42. Pires, A. L. R.and Moraes, Â. M. (2014). Improvement of the mechanical properties of chitosanalginate wound dressings containing silver through the addition of a biocompatible silicone rubber. Journal of Applied Polymer Science, n/a-n/a. doi:10.1002/app.41686

43. Pirsa, S., et al. (2020). Preparation of biodegradable composite starch/tragacanth gum/ Nanoclay film and study of its physicochemical and mechanical properties. Chemical Review and Letters, 3, 9 .

44. Popescu, M.-C., et al. (2017). The influence of cellulose nanocrystals content on the water sorption properties of bio-based composite films. Materials \& Design, 132, 170-177. doi:10.1016/j.matdes.2017.06.067

45. Ranjbar-Mohammadi, M., et al. (2013). Fabrication of novel nanofiber scaffolds from gum tragacanth/poly(vinyl alcohol) for wound dressing application: in vitro evaluation and antibacterial properties. Mater Sci Eng C Mater Biol Appl, 33(8), 4935-4943. doi:10.1016/j.msec.2013.08.016

46. Ranjbar-Mohammadi, M., et al. (2016). Gum tragacanth/poly(l-lactic acid) nanofibrous scaffolds for application in regeneration of peripheral nerve damage. Carbohydr Polym, 140, 104-112. doi:10.1016/j.carbpol.2015.12.012

47. Ranjbar Mohammadi, M., et al. (2020). An excellent nanofibrous matrix based on gum tragacanth-

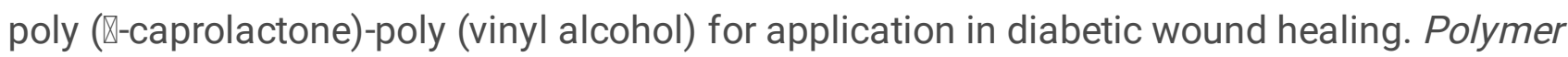
Degradation and Stability, 174. doi:10.1016/j.polymdegradstab.2020.109105

48. Rao, K. M., et al. (2017). Biodegradable Tragacanth Gum Based Silver Nanocomposite Hydrogels and Their Antibacterial Evaluation. Journal of Polymers and the Environment, 26(2), 778-788. doi:10.1007/s10924-017-0989-2

49. Rocha, G. J. M., et al. (2012). Steam explosion pretreatment reproduction and alkaline delignification reactions performed on a pilot scale with sugarcane bagasse for bioethanol production. Industrial Crops and Products, 35(1), 274-279. doi:10.1016/j.indcrop.2011.07.010 
50. Sadat Hosseini, M., et al. (2016). Synthesis of nanohydrogels based on tragacanth gum biopolymer and investigation of swelling and drug delivery. Int J Biol Macromol, 82, 806-815. doi:10.1016/j.ijbiomac.2015.09.067

51. Schoeler, M., et al. (2020). Cellulose Nanofibers from Cassava Agro-Industrial Waste as Reinforcement in Pva Films. Química Nova. doi:10.21577/0100-4042.20170542

52. Seabra, A. B., et al. (2018). Cellulose nanocrystals as carriers in medicine and their toxicities: A review. Carbohydr Polym, 181, 514-527. doi:10.1016/j.carbpol.2017.12.014

53. Silva, K. S., et al. (2016). Synergistic interactions of locust bean gum with whey proteins: Effect on physicochemical and microstructural properties of whey protein-based films. Food Hydrocolloids, 54, 179-188. doi:10.1016/j.foodhyd.2015.09.028

54. Simon, P. L. (2004). Cancer Cell Culture: Methods and Protocols. Methods In Molecular Medicine, 88.

55. Singh, B., et al. (2016). Designing tragacanth gum based sterile hydrogel by radiation method for use in drug delivery and wound dressing applications. Int J Biol Macromol, 88, 586-602. doi:10.1016/j.ijbiomac.2016.03.051

56. Singh, S., et al. (2018). Antimicrobial and antioxidant properties of polyvinyl alcohol bio composite films containing seaweed extracted cellulose nano-crystal and basil leaves extract. Int J Biol Macromol, 107(Pt B), 1879-1887. doi:10.1016/j.ijbiomac.2017.10.057

57. Slavutsky, A. M.and Bertuzzi, M. A. (2014). Water barrier properties of starch films reinforced with cellulose nanocrystals obtained from sugarcane bagasse. Carbohydr Polym, 110, 53-61. doi:10.1016/j.carbpol.2014.03.049

58. Sukyai, P., et al. (2018). Effect of cellulose nanocrystals from sugarcane bagasse on whey protein isolate-based films. Food Res Int, 107, 528-535. doi:10.1016/j.foodres.2018.02.052

59. Sun, X., et al. (2017). Nanocellulose films with combined cellulose nanofibers and nanocrystals: tailored thermal, optical and mechanical properties. Cellulose, 25(2), 1103-1115. doi:10.1007/s10570-017-1627-9

60. Sutka, A., et al. (2015). Enhanced stability of PVA electrospun fibers in water by adding cellulose nanocrystals. Holzforschung, 69(6), 737-743. doi:10.1515/hf-2014-0277

61. Taghavizadeh Yazdi, M. E., et al. (2021). Gum Tragacanth (GT): A Versatile Biocompatible Material beyond Borders. Molecules, 26, 1510. doi:10.3390/molecules26061510

62. Taukoorah, U., et al. (2016). Piper betle L. (betel quid) shows bacteriostatic, additive, and synergistic antimicrobial action when combined with conventional antibiotics. South African Journal of Botany, 105, 133-140. doi:10.1016/j.sajb.2016.01.006

63. Tavakol, M., et al. (2014). Synthesis and Characterization of an Enzyme Mediated in situ Forming Hydrogel Based on Gum Tragacanth for Biomedical Applications. Iranian Journal of Biotechnology, 12(1). doi:10.5812/ijb.15811

64. Teodorescu, M., et al. (2019). Biomaterials of PVA and PVP in medical and pharmaceutical applications: Perspectives and challenges. Biotechnol Adv, 37(1), 109-131. doi:10.1016/j.biotechadv.2018.11.008 
65. Tong, W. Y., et al. (2017). Antimicrobial wound dressing film utilizing cellulose nanocrystal as drug delivery system for curcumin. Cellulose, 25(1), 631-638. doi:10.1007/s10570-017-1562-9

66. Tonyali, B., et al. (2018). Physicochemical and microstructural characterization of gum tragacanth added whey protein based films. Food Research International, 105, 1-9. doi:10.1016/j.foodres.2017.10.071

67. Umar, R. A., et al. (2018). Chemical Composition and The Potential Biological Activities of Piper Betel - A review. Malaysian Journal of Applied Sciences, 3(1), 8.

68. Vanitjinda, G., et al. (2019). Effect of xylanase-assisted pretreatment on the properties of cellulose and regenerated cellulose films from sugarcane bagasse. Int J Biol Macromol, 122, 503-516. doi:10.1016/j.ijbiomac.2018.10.191

69. Wahid, F., et al. (2019). Reusable ternary PVA films containing bacterial cellulose fibers and epsilonpolylysine with improved mechanical and antibacterial properties. Colloids Surf B Biointerfaces, 183, 110486. doi:10.1016/j.colsurfb.2019.110486

70. Xu, L., et al. (2020). Preparation and Properties of Cyanobacteria-Based Carbon Quantum Dots/Polyvinyl Alcohol/ Nanocellulose Composite. Polymers, 12(5), 1143. doi:10.3390/polym12051143

71. Yadav, I., et al. (2017). Synthesis and characterization of polyvinyl alcohol- carboxymethyl tamarind gum based composite films. Carbohydr Polym, 165, 159-168. doi:10.1016/j.carbpol.2017.02.026

72. Zarekhalili, Z., et al. (2017). Fabrication and characterization of PVA/Gum tragacanth/PCL hybrid nanofibrous scaffolds for skin substitutes. Int J Biol Macromol, 94(Pt A), 679-690. doi:10.1016/j.ijbiomac.2016.10.042

73. Zhang, D., et al. (2015). Carboxyl-modified poly(vinyl alcohol)-crosslinked chitosan hydrogel films for potential wound dressing. Carbohydr Polym, 125, 189-199. doi:10.1016/j.carbpol.2015.02.034

74. Zhao, X., et al. (2017). Antibacterial anti-oxidant electroactive injectable hydrogel as self-healing wound dressing with hemostasis and adhesiveness for cutaneous wound healing. Biomaterials, 122, 34-47. doi:10.1016/j.biomaterials.2017.01.011

75. Zheng, C., et al. (2019). Effective wound dressing based on Poly (vinyl alcohol)/Dextran-aldehyde composite hydrogel. Int J Biol Macromol, 132, 1098-1105. doi:10.1016/j.ijbiomac.2019.04.038

\section{Figures}



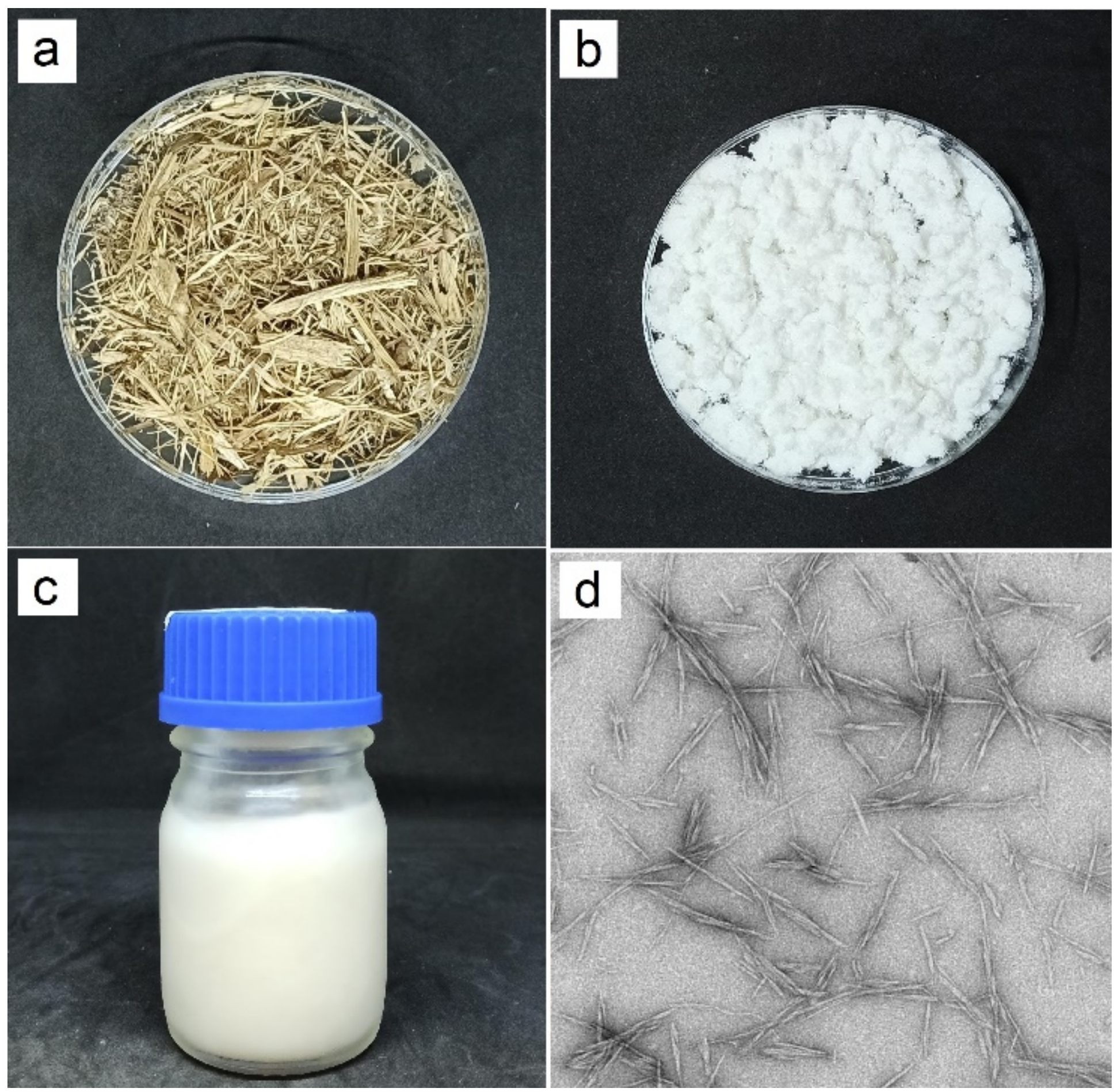

Figure 1

Photographs of (a) SCB, (b) bleached fiber, (c) CNCs, and (d) TEM image of CNCs. 


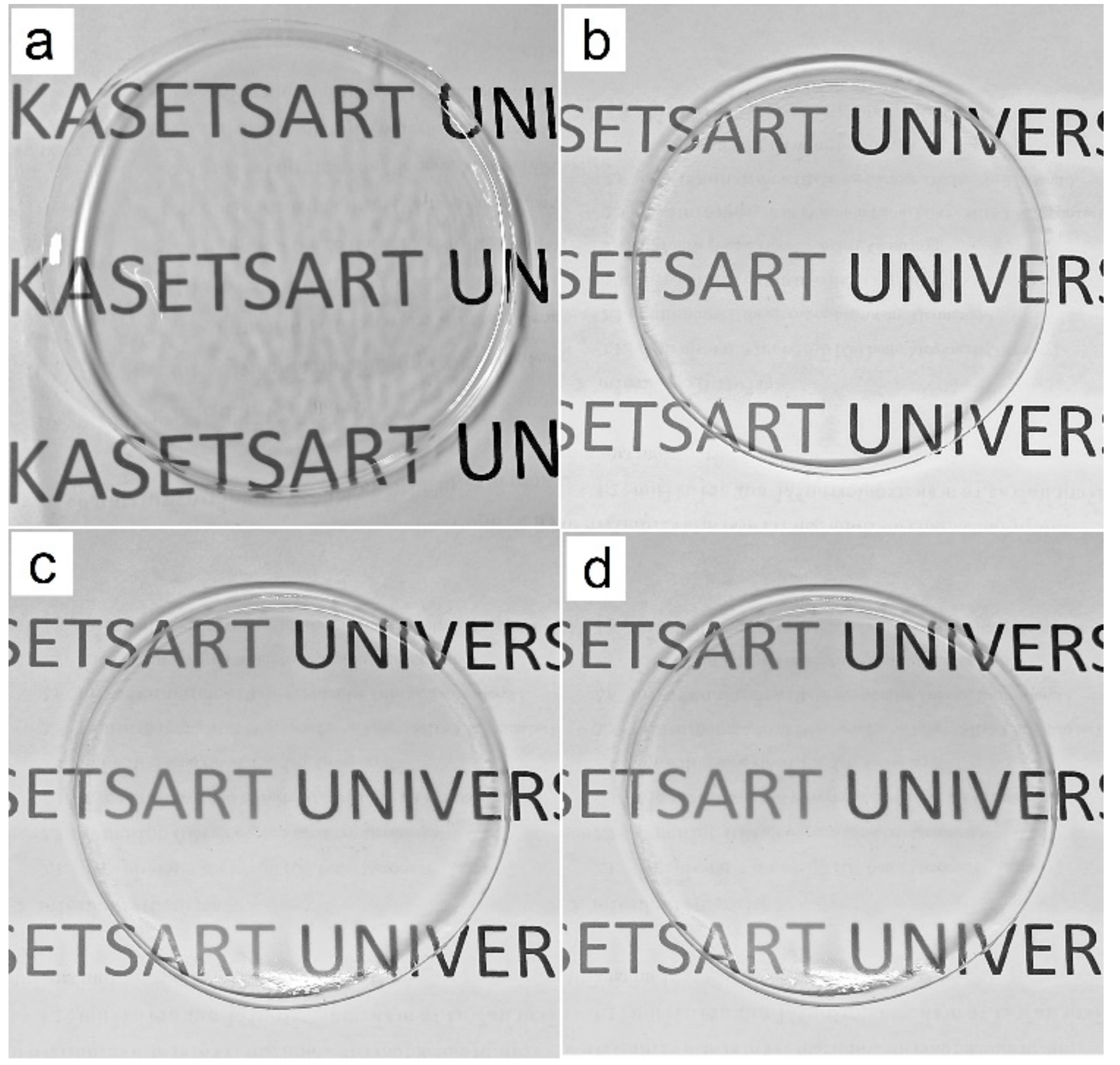

Figure 2

Photographs of (a) PVA, (b) PVA/GT, (c) PVA/GT/CNC2, and (d) PVA/GT/CNC10. 


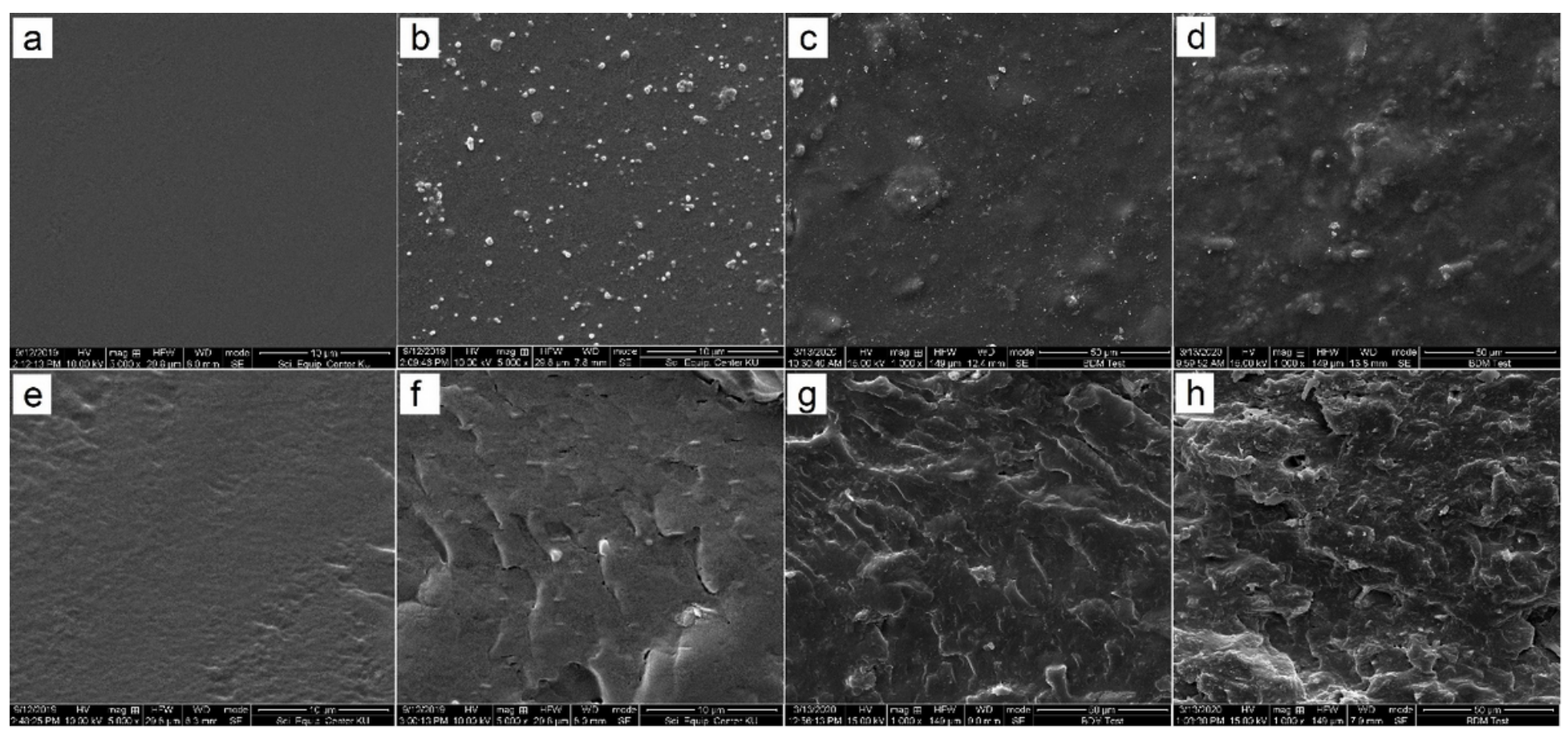

Figure 3

SEM micrographs of surface of (a) PVA film, (b) PVA/GT film, (c) PVA/GT/CNC2, (d) PVA/GT/CNC10, and cross section of (e) PVA film, (f) PVA/GT film, (g) PVA/GT/CNC2 and (h) PVA/GT/CNC10.

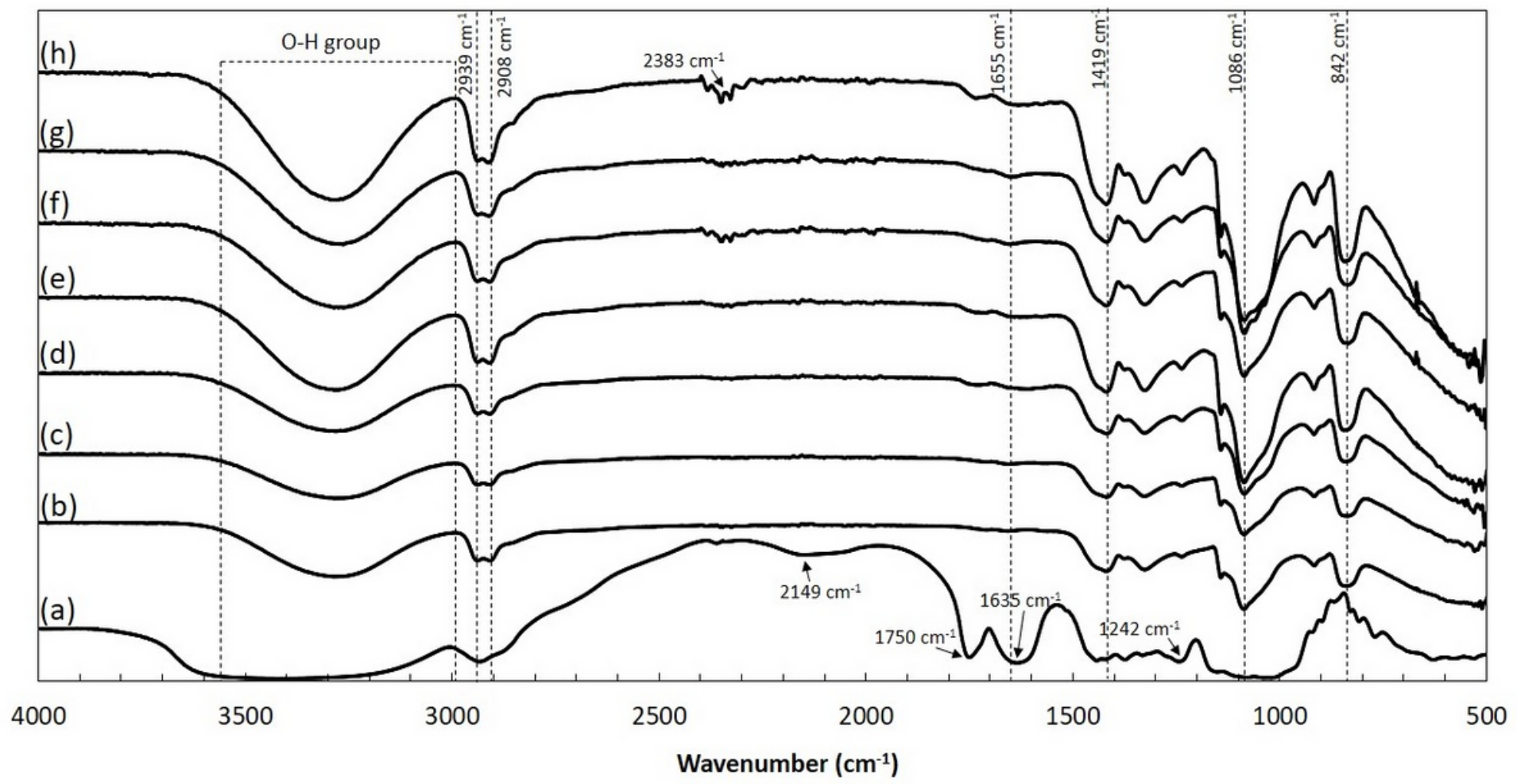

Figure 4 
FTIR spectra of (a) GT, (b) PVA, (c) PVA/GT, (d) PVA/GT/CNC2, (e) PVA/GT/CNC4, (f) PVA/GT/CNC6, (g) PVA/GT/CNC8, and (h) PVA/GT/CNC10.

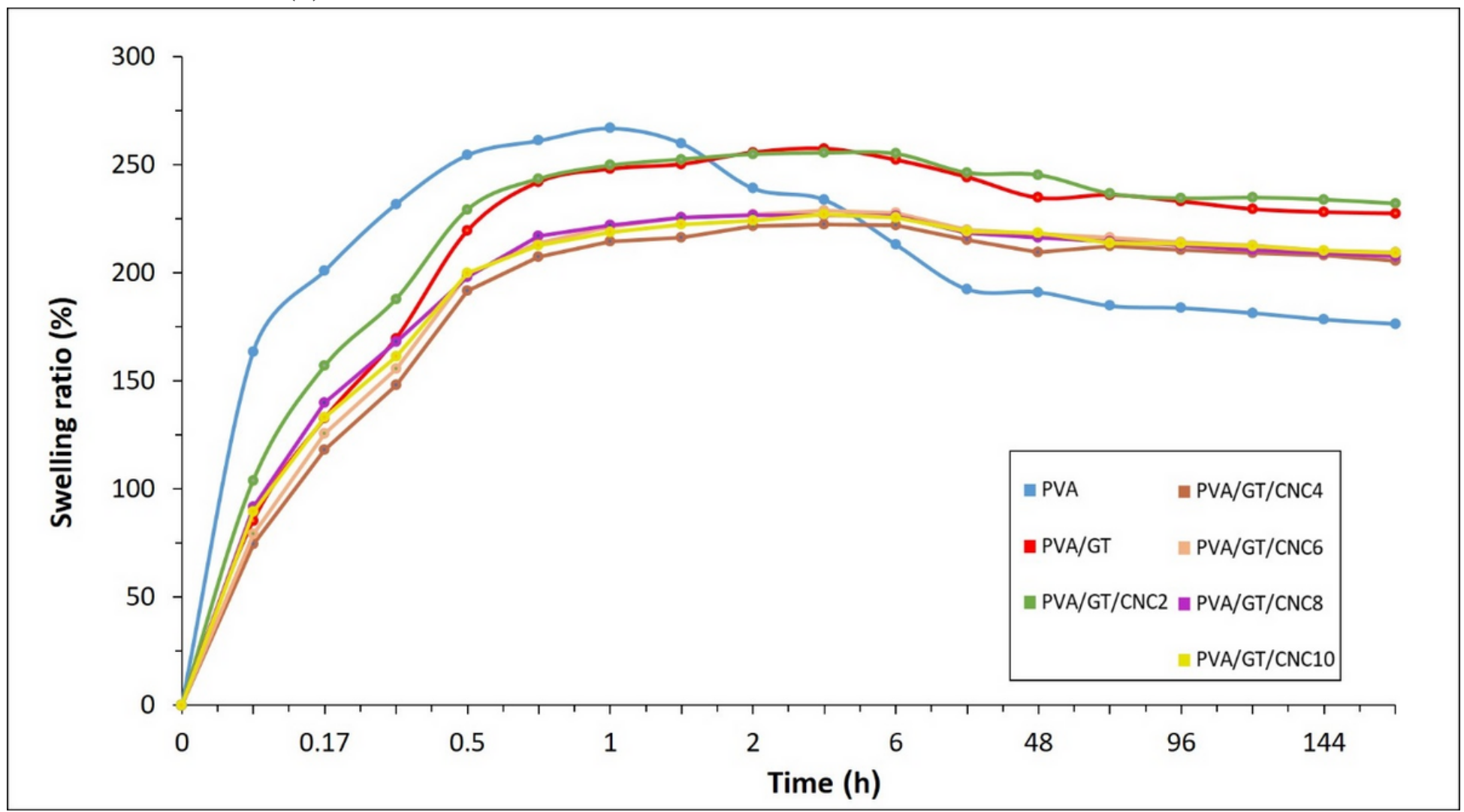

Figure 5

Swelling ratio of composite films for 7 days.

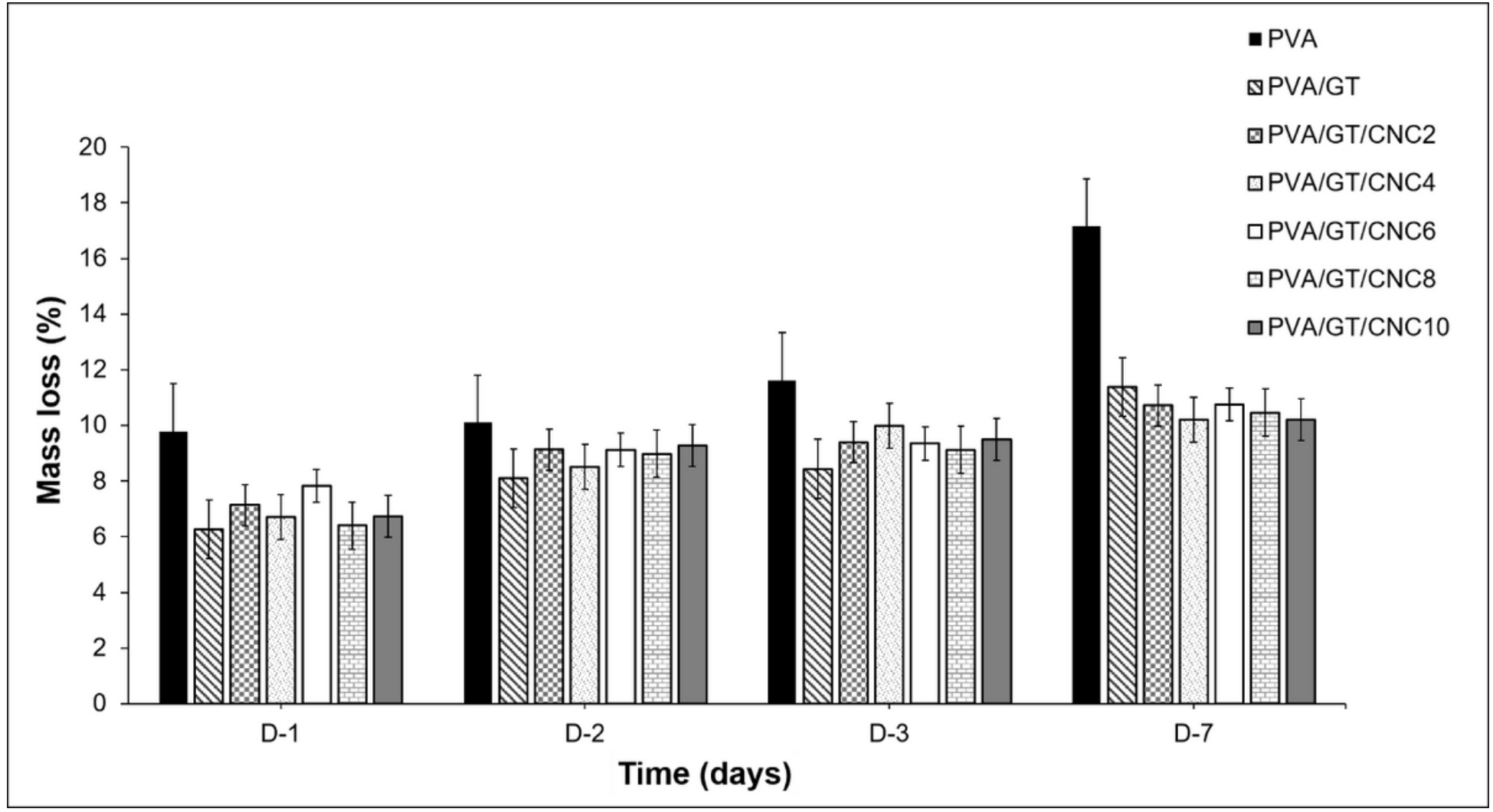


Figure 6

Percentage of weight loss after 7 days.

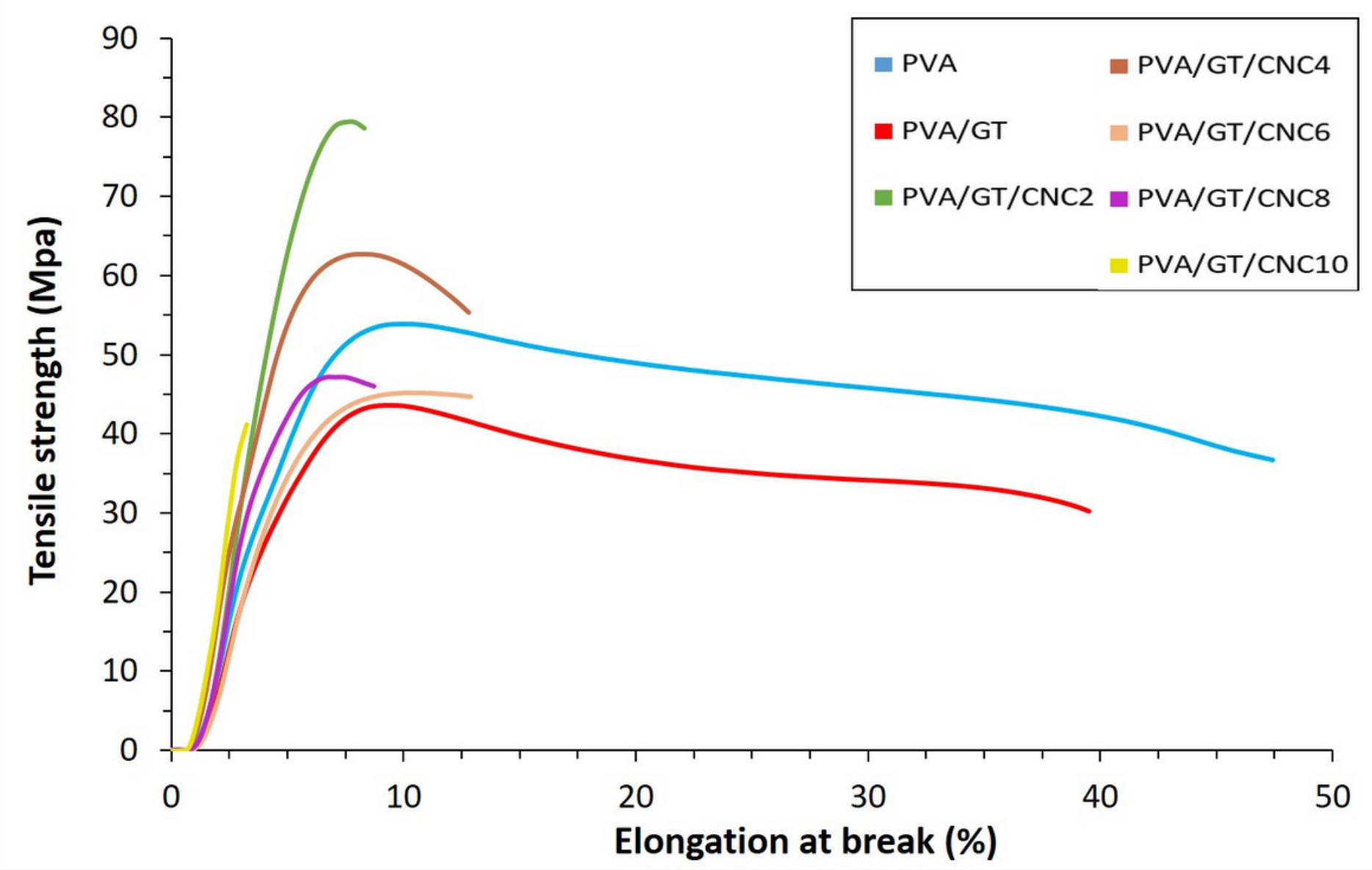

Figure 7

Stress - strain curves of PVA, PVA/GT, PVA/GT/CNC2 and PVA/GT/CNC10. 


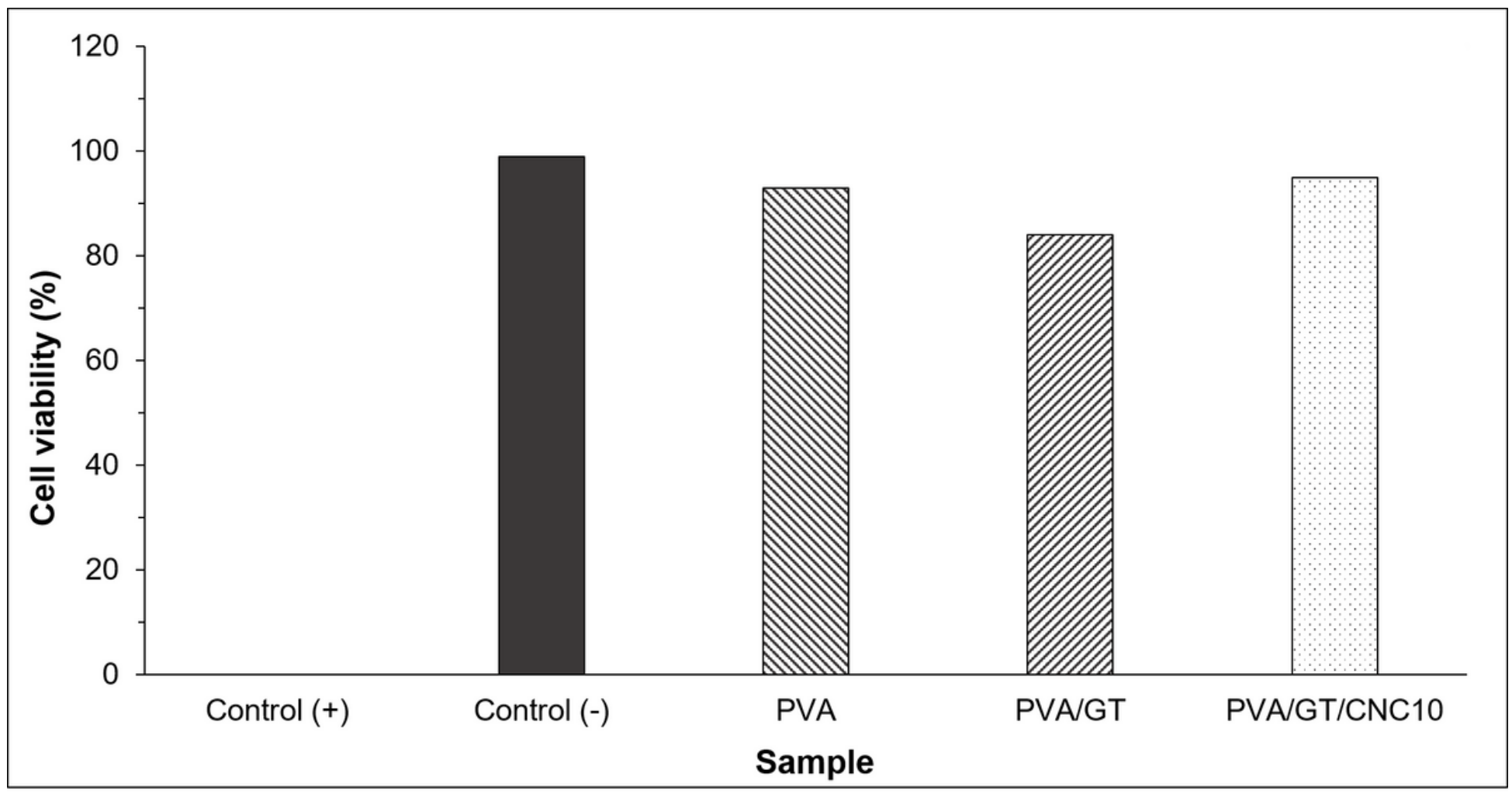

Figure 8

Cell viability of PVA, PVA/GT and PVA/GT/CNC10, comparing with positive and negative controls.
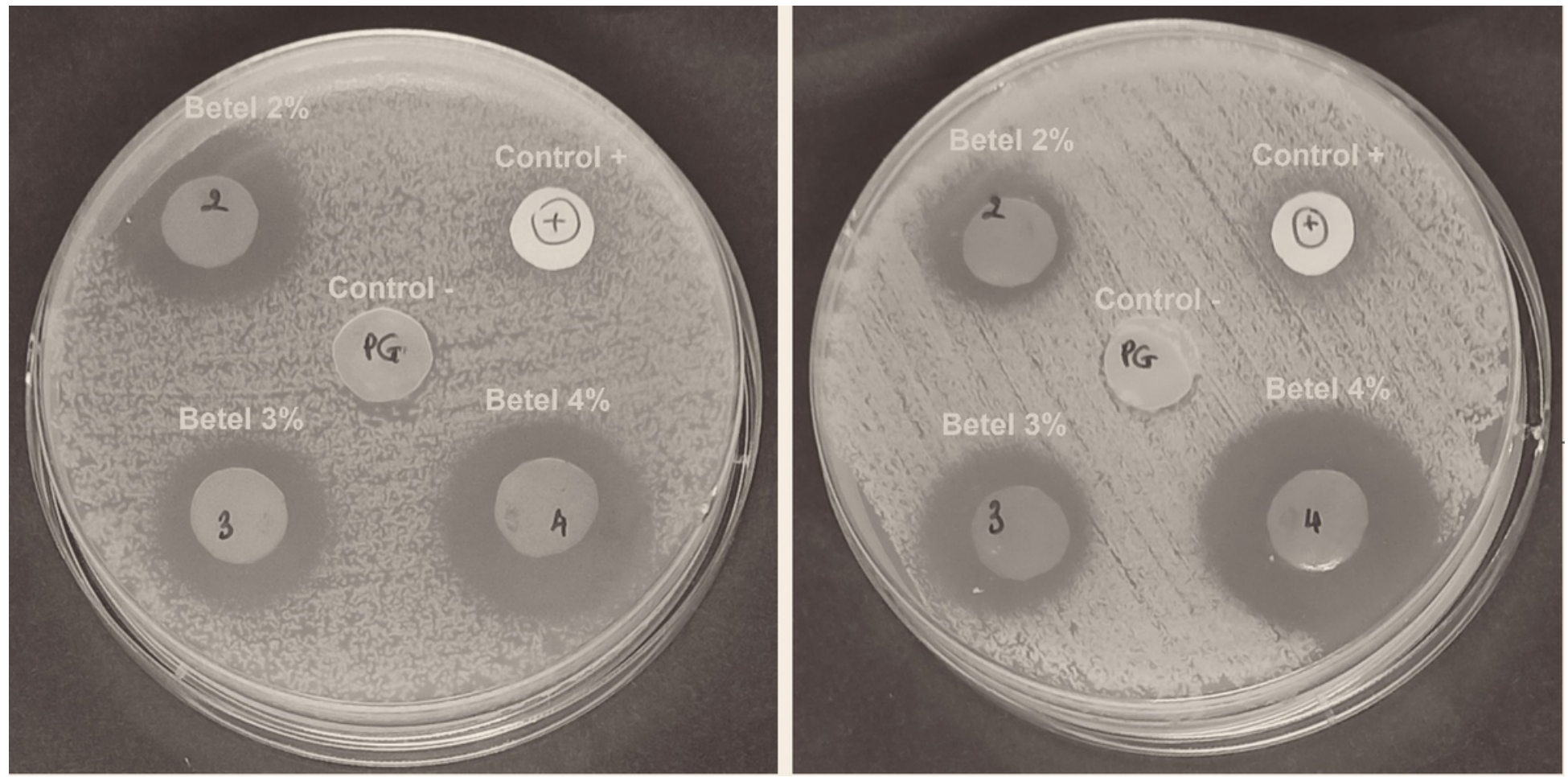

Figure 9

Antibacterial activity PVA/GT/CNC2 film loading $2 \%, 3 \%$ and $4 \%$ of crude betel extract against $P$. aeruginosa (left) and S. aureus (right). 